\title{
ARTICLE
}

\section{Development of a Grab-sampling Type Multitubular Proportional Counter for Measurement of Radon Concentration in Atmosphere}

\author{
Wataru KADA*, Nidal DWAIKAT, Masato SUEYASU, Jun DATEMICHI, Fuminobu SATO, Isao MURATA, \\ Yushi KATO, and Toshiyuki IIDA
}

Graduate School of Engineering, Osaka University, Yamada-oka, Suita, Osaka 565-0871, Japan

\begin{abstract}
A grab-sampling type multitubular proportional counter was developed to measure radon concentration in atmosphere. Thirty-one proportional counters were assembled inside an acrylic tube. Each counter was made up with the $30 \mathrm{~mm} \Phi$ stainless steel tube and $50 \mu \mathrm{m} \Phi$ tungsten anode wire. The effective volume of the assembled multitubular proportional counter was about 10 litters. Furthermore, a compact ventilation apparatus, a high efficiency particulate air (HEPA) filter, a desiccant agent, a heater and related modular electronic circuits were added to the proportional counter to improve its performance and stability during operation. When air is injected into the proportional counter, the filter separates radon gas from dusts with radon daughters. The desiccant agent and the heater control humidity, which deteriorates the gas multiplication for the proportional counter. This proportional counter was directed to measure alpha-rays from ${ }^{214} \mathrm{Po}$. The energy resolution of the system was sufficient to ensure the separation of the peak of ${ }^{214} \mathrm{Po}$ alpha rays. Measured variation in counting rate of ${ }^{214} \mathrm{Po}$ alpha-rays after the air inhalation well agreed with that calculated from the decay scheme of ${ }^{222} \mathrm{Rn}$. It was confirmed radon concentration in atmosphere was successfully evaluated from the analysis of counting data measured by the present system.
\end{abstract}

\section{KEYWORDS: multitubular proportional counter, grab-sampling type, radon monitoring, ${ }^{214}$ Po, alpha-ray} detection

\section{Introduction}

Radon is a gaseous radioactive element distributed naturally in our living environment ${ }^{1}$. It is easily diffused from the ground and enters a lung of a human being ${ }^{2}$. The exposure to radon is inescapable. Radon gas naturally has a tendency to accumulate in a confined place with poor air ventilation. Thus its concentration in atmosphere attracts growing interest in many countries from a point of the risk of suffering from lung cancer.

Indoor radon surveys have been most intensively carried out in many countries to estimate the relation between radon concentration and its effects on the human bodies ${ }^{3-5)}$. Solid-state nuclear track detectors have been widely used for this measurements ${ }^{6,7)}$. Many efforts have been done to improve the sensitivity of the track detectors ${ }^{8-10)}$. However, they are suffering from several problems; for example, they need a long exposure and processing time to detect tracks made by environmental radiation. Radon radioactivity in air varies and depends on atmospheric conditions, and its continuous measurement is not so easy. Therefore the online measurement of radon radioactivity is desirable for radiation safety and management ${ }^{11)}$.

A more effective and suitable detector is needed for the measurement of radon radioactivity in atmosphere. An air-flow ionization detector takes a sample of air into the chamber and measures its radioactivity directly ${ }^{12,13)}$. Many technical efforts have been made for the improvement of tolerance characteristics of ionization detectors against high humidity, severe temperature and others ${ }^{14-17)}$.

The major aim of this study is to build a reliable,

*Corresponding Author, E-mail: kada@nf.eie.eng.osaka-u.ac.jp

(C) Atomic Energy Society of Japan inexpensive and sensitive air-filled detector that measures indoor radon radioactivity. Several unique techniques were introduced in the detector and related components, and the whole system was optimized to measure the radon activity in atmosphere.

\section{Construction}

\section{Multitubular Proportional Counter}

A grab-sampling type multitubular proportional counter assembly was developed for the measurement of radon concentration in atmosphere. The whole system consists of an assembly of proportional counters for radon detection, a simple ventilation apparatus and related electronic circuits modules. A schematic drawing of the assembly of the detector is shown in Fig. 1. Thirty-one open-type proportional counters $(30 \mathrm{~mm} \Phi \times 500 \mathrm{~mm})$ were set in an acrylic tube $(200 \mathrm{~mm} \Phi \times 580 \mathrm{~mm})$. All the counters were made up with the same $30 \mathrm{~mm} \Phi$ stainless steel tubes (cathode) and a $51 \mu \mathrm{m} \Phi$ tungsten wires (anode). By assembling thirty proportional counters, we eventually made a radon detector with a large volume of about 10 liters.

The top and bottom of the acrylic tube were covered by $10 \mathrm{~mm}$ thick nylon plates and were sealed with rubber packing. As shown in Fig.1, the acrylic tube was fitted with three gas valves. Samples of air and nitrogen gas for the purgation were fed into the acrylic tube through each valve. The acrylic tube was evacuated with a vacuum pump through the valve near the bottom lid. The top nylon plate was fitted with thirty-one feedthroughs. Each feedthrough was connected to the anode wire of each proportional counters. The top nylon plate was covered with an aluminum box for the electrical and mechanical shield. 


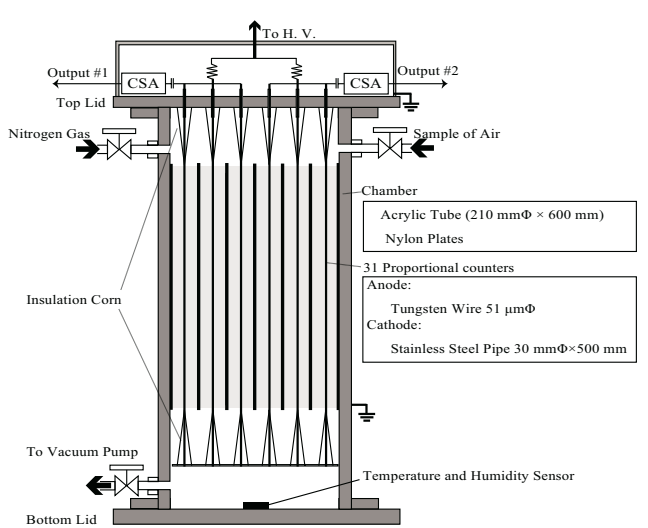

Fig. 1 Schematic drawing of grab-sampling type multitubular proportional counter

\section{Electronic Circuit Modules}

Three charge sensitive amplifiers (CSAs) and high voltage circuits were placed inside the aluminum box, which was fitted with several signal and high voltage connectors. Figure 2 shows a block diagram of electronic circuit modules for the multitubular proportional counter. Each electronic circuit module was adjusted to detect radon-related alpha-rays separately from the backgrounds. The thirty-one proportional counters were divided into three groups. A central proportional counter (group A) had a lantern wick (i.e. an alpha source) on the surface of the cathode tube, and this counter was used for checking the system. The remainder 30 counters were halved, and the anode wires of the 15 counters were connected together. As shown in Fig.2, signals from each group (A, B and C) of the counters were fed to each CSA.

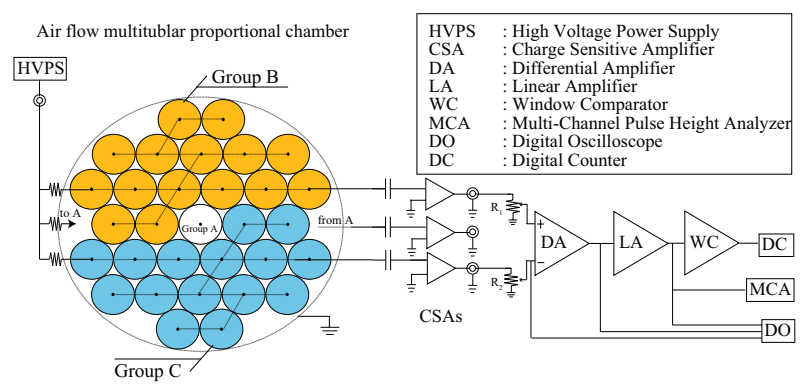

Fig. 2 Schematic diagram of electronic circuits for grab-sampling type multitubular proportional counter

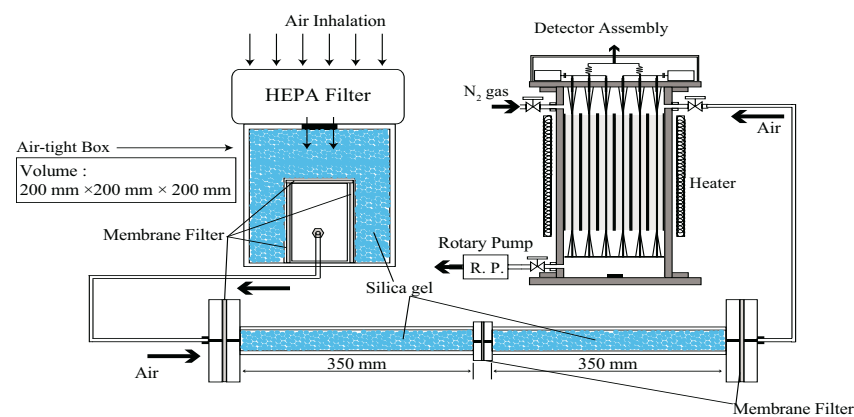

Fig. 3 Schematic drawing of air filter modules for grab-sampling type multitubular proportional counter
To cancel the common-mode noises for $\mathrm{B}$ and $\mathrm{C}$ groups, output signals from each CSA were fed to a differential amplifier (DA). The gain of the two CSAs was precisely adjusted by variable resistors (R1, R2). The optimum adjustment for the noise cancellation was confirmed from the noise reduction observed with a digital oscilloscope. Output signals of the DA were then fed into a Linear Amplifier (LA) with a shaping time of $0.5 \mu$ s. Both positive and negative output pulses were produced from the LA because output signals from each CSA were reciprocally amplified by the DA.

The positive pulses were directly analyzed with a multi-channel analyzer (MCA), while the negative pulses were done after inversion. Both positive and negative pulses were also converted into logic signals for the pulse counting by a window comparator (WC). The positive and negative threshold voltages of the WC were appropriately determined from data on pulse height distributions measured with the MCA.

\section{Air Filter Modules}

The multitubular proportional counter was supplied with a high efficiency particulate air (HEPA) filter. The HEPA filter and further membrane filters are effective in the removal of the radon daughters when air is injected into the counter. The filter should be useful to the follow-up of the variation in radioactivity of radon and its progenies inside the detector. The radon concentration can be calculated from the analysis of such variations. Figure 3 shows a schematic drawing of air filter modules for the grab-sampling type multitubular proportional counter.

Additional improvements were done to reduce humidity inside the counter. Silica gel was put in the air filter modules to reduce humidity, which deteriorates the gas multiplication for the proportional counter. Moreover, the acrylic tube was bound with a heater to control the temperature of air inside the detector. A humidity and temperature sensor was also set inside the acrylic tube to check the condition of air. The HEPA filter module was placed on an air-tight box $(250 \mathrm{~mm}$ $\times 250 \mathrm{~mm} \times 250 \mathrm{~mm}$ ). A $150 \mathrm{~mm} \Phi$ hole was made on the top lid of the box and through the hole air was fed into the box from the HEPA filter module. The air-tight box was filled with silica gels. A set of the membrane filters was also placed inside the box. The membrane filters are effective in the removal of smaller dusts which can pass through the HEPA filter. Another air filter was made up with a $20 \mathrm{~mm} \Phi$ plastic pipe. The plastic pipe was filled with silica gel and membrane filters were placed at each terminal of the pipe. Eventually a sample of air was fed into the acrylic tube through the HEPA filter, the air-tight box with silica gel and membrane filters and the similar pipe filter.

Figure 4 shows an example of variations of humidity inside the acrylic tube. The relative humidity of natural air was over $50 \%$ in the acrylic tube and in the room. Once the air filter system was operated, the relative humidity of air inhaled through the filter soon decreased and settled down to about $10 \%$. After ten minutes, natural air was fed again into the acrylic tube without the filter. The relative humidity of the inhaled air returned to the former level. 


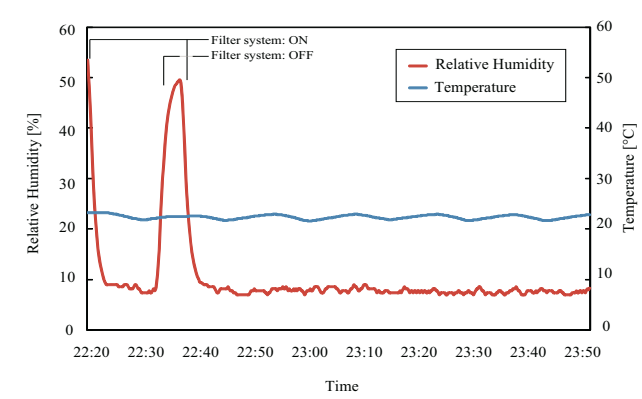

Fig. 4 Variation of humidity and temperature

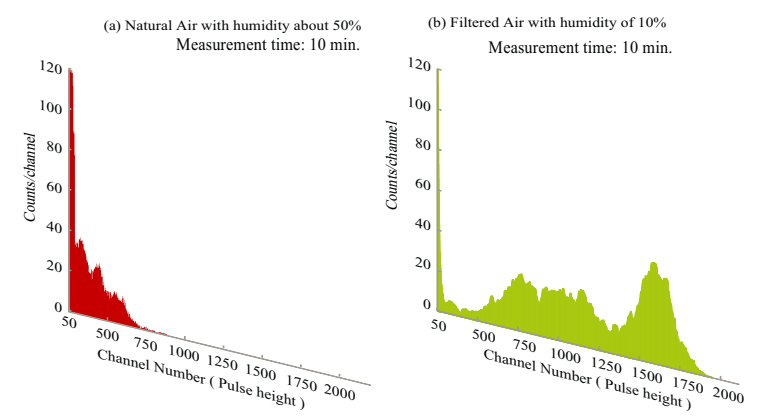

Fig. 5 Pulse height distributions of grab-sampling type multitubular proportional counters for different samples

Temperature inside the acrylic tube was kept around 298 $\mathrm{K}$. It was confirmed that the humidity and temperature of a sample of air was successfully controlled in the acrylic tube with the present air filter system.

\section{Experiments}

At first, fundamental characteristics of the central windowless air proportional counter (group A) were examined by use of alpha-rays from the lantern wick. The pulse height distributions of the proportional counter for the alpha rays were measured under various electrical and air conditions. The bias voltage of $+3 \mathrm{kV}$ was eventually applied to the anode wire. A peak, which corresponds to the alpha-rays from the lantern wick, was clearly measured with the similar electronics circuits as shown in Fig.2.

Then several tests were performed for the examination of characteristics of the multitubular proportional counter (group B, C). Actual indoor radon monitoring was done. Related electronics components and the air filter modules were also checked under different environmental conditions. The process of measurement with the grab-sampling type multitubular proportional counter was accomplished by the following five steps.

1) Evacuate the acrylic tube with a vacuum pump.

2) Inject nitrogen gas into the acrylic tube to clean its inside up from any contamination.

The contamination of alpha radioactivity can be checked by the operation of the counter. Return to the step 1) if the level of alpha radioactivity is too high.

3) Evacuate the acrylic tube again.

4) Inject a sample of air into the acrylic tube through the air filter modules for about 5 minutes.

5) Close all valves, check the air conditions and start the measurement.
The series of the processes ensure that the inside of the tube is free from contamination of alpha radioactivity and that only radon is injected into the tube through the air filter.

Pulse height response of the grab-sampling type multitubular proportional counter to alpha rays from radon and other radioactive nuclei was measured with the digitalized oscilloscope and the MCA. Furthermore, in some cases, a commercially available and calibrated radon monitor was used together with the present system, and then measured data were compared between the monitor on the market and the present system.

\section{Results and Discussion}

\section{Pulse Height Distributions for Air with/without Filter}

An open-type proportional counter responds to natural gamma-rays, cosmic rays, radiations from radioactive nuclei in the counter itself and others. Especially, alpha radioactivity in air induces large pulse signals for one proportional counter.

Figure 5 shows examples of pulse height distributions of the grab-sampling type multitubular proportional counters for different samples of air. Figure 5(a) shows an example for natural air inhaled without the air filter and an example for air with the filter is shown in Fig.5 (b). The relative humidity of the natural air was about $50 \%$ and no clear peak was observed in the larger pulse height region of the spectrum (Fig.5 (a)). This means that the humidity deteriorated the detection characteristics of the multitubular proportional counter for alpha rays. As for filtered air, on the other hand, a broad but clear peak was observed in the pulse height spectrum (Fig. 5(b)). The relative humidity of the air inhaled through the air filter was about $10 \%$ and it was confirmed that similar clear peaks around 1600 channels were observed for other samples of air. It should be noted from the figure high energy alpha-rays can be sufficiently distinguished with the multitubular proportional counter together with the air filter.

\section{Variations of Alpha-ray Spectra after Air Inhalation}

Since an alpha ray from ${ }^{214}$ Po has the highest energy among alpha rays from ${ }^{222} \mathrm{Rn}$ and its daughter and granddaughter, the present system is directed mainly to the detection of alpha rays from ${ }^{214} \mathrm{Po}$. The energy of an alpha ray from ${ }^{214} \mathrm{Po}$ is about 7.7 $\mathrm{MeV}$ and is so large that the grab-sampling type multitubular proportional counter can distinguish such alpha rays. As dust with polonium is removed by the air filter and air containing only radon is injected into the proportional counter, the growth of ${ }^{214}$ Po can be precisely measured under the operation of the counter after the air injection. Then the radon concentration in air can be calculated from the radioactive equilibrium law on radon and polonium.

Figure 6 (a), (b), (c) and (d) shows examples of variations of pulse height spectrum of the grab-sampling type multitubular proportional counter for a sample of air inhaled through the filter. Each pulse height spectrum was measured for 5 minutes. As shown in Fig.6, no peak was observed in the larger pulse height region around 1600 channels soon after the air inhalation (Fig.6 (a)). And counts gradually increased in the region around 1600 channels (Fig.6 (b), (c)). Then a clear peak was observed in the same region around 1600 channels two hours after the air inhalation (Fig.6 (d)). It was confirmed 
from a series of the pulse height spectra that the radioactivity of the emission of higher energy alpha rays gradually increased in the counter. The origin of this peak can be identified from the rate of increase in the counts in the region around 1600 channels.
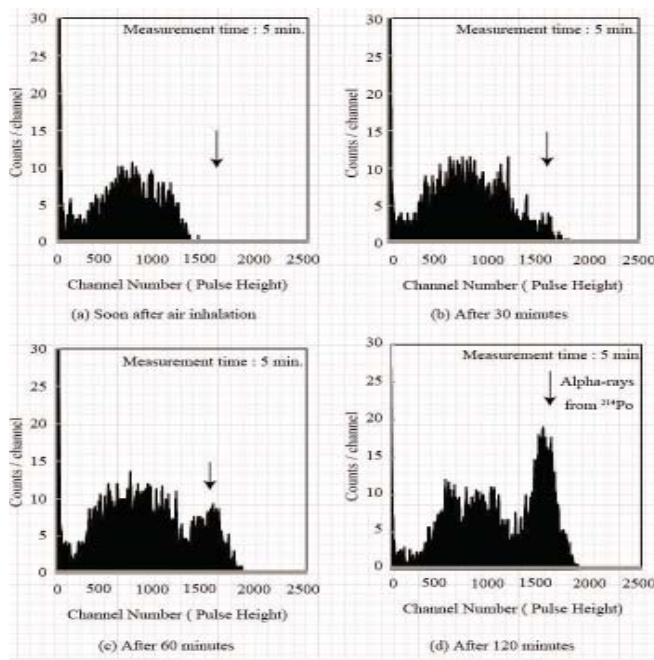

Fig. 6 Variations of pulse height spectrum of grab-sampling type multitubular proportional counter for a sample of air inhaled through the filter.

\section{Detection of Alpha Rays from ${ }^{214} \mathrm{Po}$}

As the half life of ${ }^{222} \mathrm{Rn}$ is about 3.8 days and is much longer than that of its related radioactive nuclei, namely ${ }^{218} \mathrm{Po}$, ${ }^{214} \mathrm{~Pb},{ }^{214} \mathrm{Bi}$ and ${ }^{214} \mathrm{Po}$, the concentration of ${ }^{222} \mathrm{Rn}$ in air can be estimated on the basis of the radioactive equilibrium from that of ${ }^{222} \mathrm{Rn}$-related nucleus, concretely ${ }^{214} \mathrm{Po}$ in air. The radioactivity of ${ }^{214} \mathrm{Po}$ becomes approximately equal to that of ${ }^{222} \mathrm{Rn}$ sufficiently long time after the air inhalation in the counter. The counting rate of the high-energy alpha rays can be easily measured with the window-type discriminator to count the peak around 1600 channels, as described in the former section.

Figure 7 shows an example of the increase in the counting rate of the high-energy alpha rays measured with the grab-sampling type multitubular proportional counter after the air inhalation. The width of the window of the discriminator was fitted for the peak around 1600 channels. Measured data on the counting rate agreed well with a curve of the radioactivity of ${ }^{214} \mathrm{Po}$, which was obtained from calculations on the basis of the radioactive equilibrium on radon and polonium. This result means that the peak around 1600 channels was derived from ${ }^{214} \mathrm{Po}$. As shown in Fig.7, changes of the radioactivity of ${ }^{218} \mathrm{Po}$ and ${ }^{222} \mathrm{Rn}$ were also calculated on the basis of data on ${ }^{214} \mathrm{Po}$ and the volume of the multitubular proportional counter. The results in Fig.7 indicate that the concentration of ${ }^{222} \mathrm{Rn}$ in air, which was injected into the multitubular proportional counter, was about $35 \mathrm{~Bq} / \mathrm{m}^{3}$. The calibrated radon monitor set in the same room indicated on the whole the same value, although a precise calibration experiment, e.g. an injection of a standard air containing a fixed concentration of radon, is needed to precisely evaluate the sensitivity of the present system, i.e. the grab-sampling type multitubular proportional counter with the air filters.

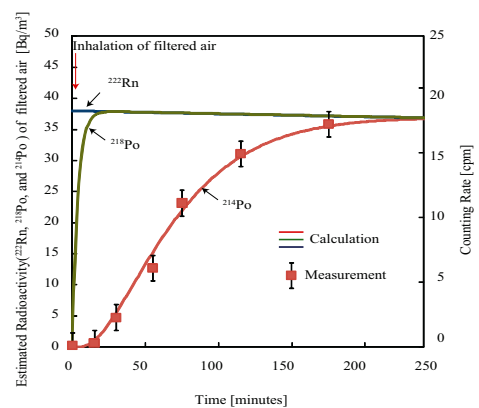

Fig. 7 Increase in the counting rate of high-energy alpha rays measured with grab-sampling type multitubular proportional counter after air inhalation.

\section{Conclusion}

The grab-sampling type multitubular proportional counter was successfully developed for the sensitive measurement of the radon concentration in air. To cancel the common-mode noises, the thirty-one open-type proportional counters were symmetrically assembled inside the acrylic tube. Furthermore, the humidity inside the counter was well controlled with the air filter containing the desiccant agent and the heater.

The present system was directed to the detection of the high-energy alpha rays from ${ }^{214}$ Po. After the air inhalation, the measured data on the change of the counting rate of the high-energy alpha rays agreed well with the change of the radioactivity of ${ }^{214} \mathrm{Po}$, which was calculated on the basis of the radioactive equilibrium on radon and polonium. It was confirmed that the radon concentration in air was successfully evaluated from the analysis on the counting data measured with of the present system.

\section{References}

1) Information Sheet, Radon and Health, World Health Organization (WHO), (2004).

2) B. Lau, D. Nikezic, K. Yu, Radiat. Prot. Dos. 122, 534 (2006).

3) T. Iyogi, S. Ueda, S. Hisamatsu, et al, J. Environ. Radioact. 67, $91(2003)$.

4) M. Doi, K. Fujimoto, S. Kobayashi, et al, Health Phys. 66, 43 (1994).

5) Report to the General Assembly, UNSCEAR (2000).

6) N. Ahmed, Matiullah, A. Khatibeh, et al, Radiat. Meas. 28, 341 (1997).

7) M. Al-Jarallah, J. Environ Radioact. 5, 391 (2001).

8) N. Yasuda, K. Namiki, Y. Honma, et al, Radiat. Meas., 40 [2-6], 311 (2005).

9) B. Jaleh, P. Parvin, K. Mirabaszadeh and M. Katouzi, Radiat. Meas., 38 [2], 173 (2004).

10) S. Durrani and F. Abu-Jarad, Nucl. Instr. Meth., B. 100 [1], 97 (1995).

11) S. Yamamoto, K. Tarutani, K. Yamasoto, et al, IEEE Trans. Nucl. Sci. 48, 391 (2001).

12) L. Johansson, B. Roos, C. Samuelsson, Appl. Radiat. Isotope, 43, 119 (1992).

13) W. R. Lea, Berlin Heidelberg, Corrected $2^{\text {nd }}$ printing, (1992).

14) A. Vargas and X. Ortega, Radiat. Prot. Dos. 122 , 303 (2006).

15) R. Mahat, D. Bradley, Y. Amin, et al, Radiat. Phys. Chem. 61, 489 (2001).

16) D. Mazed, R. Ciolini, G. Curzio et al, Nucl. Instr. Meth. A. 582, 535 (2007).

17) I. Busch, H.Greupner, U. Keyser, Nuci. Instr. Meth., A, 481, 330 (2002). 